\title{
The Role of Paternal Age and Occurrence of Orofacial Clefts in South Indian Population
}

Soumi Samuel ${ }^{1}$, B. Rajendra Prasad ${ }^{2}$, Thara Chandran ${ }^{3}$, Deeyah Miriam Deepak ${ }^{4}$, Shaji Thomas ${ }^{5}$, Freddy Mistry ${ }^{6}$

1,2 Department of Oral and Maxillofacial Surgery, AB Shetty Memorial Institute of Dental Sciences (ABSMIDS), Derlakatte, Mangalore, Karnataka, India, ${ }^{3}$ Department of Public Health Dentistry, AB Shetty Memorial Institute of Dental Sciences (ABSMIDS), Derlakatte, Mangalore, Karnataka, India, ${ }^{4}$ AB Shetty Memorial Institute of Dental Sciences (ABSMIDS), Derlakatte, Mangalore, Karnataka, India, ${ }^{5}$ Department of Oral and Maxillofacial Surgery, People's College of Dental Sciences and Research, Bhopal, Madhya Pradesh, India, ${ }^{6}$ Department of Dentistry, University of Toronto, Ontario, Canada.

\section{ABSTRACT}

\section{BACKGROUND}

The association between orofacial cleft and parental age is evident. This study focuses on paternal age playing a vital role in the birth of children with orofacial clefts. We wanted to assess the role of paternal age as a factor in the development of congenital anomalies in this study.

\section{METHODS}

A case control study was performed on 1000 cases and 250 controls in Mangalore. The parents were interviewed regarding their age at the time of conception.

\section{RESULTS}

$46.4 \%$ of fathers of the cleft children belonged to 30 - 34 years of age group and 25 $\%$ belonged to 25 - 29 years of age group at the time of conception. In the control group, $38 \%$ belonged to 30 - 34 years of age group and $24.8 \%$ belonged to 25 - 29 years of age group.

\section{CONCLUSIONS}

Paternal age in the age group of 30 - 34 years has significant contribution in the birth of orofacial children with cleft deformities.

\section{KEY WORDS}

Orofacial cleft, Paternal Age, Congenital anomalies
Corresponding Author:

Dr. Thara Chandran,

Department of Public Health Dentistry,

$A B$ Shetty Memorial Institute of Dental Sciences (ABSMIDS), Derlakatte,

Mangalore, Karnataka, India.

E-mail: tarachandran@gmail.com

DOI: $10.14260 /$ jemds/2021/504

How to Cite This Article:

Samuel S, Prasad BR, Chandran T, et al. The role of paternal age and occurrence of orofacial clefts in South Indian population. J Evolution Med Dent Sci 2021;10(31): 2465-2469,

10.14260/jemds/2021/504

Submission 24-02-2021,

Peer Review 01-06-2021,

Acceptance 08-06-2021,

Published 02-08-2021.

Copyright (C) 2021 Soumi Samuel et al. This is an open access article distributed under Creative Commons Attribution License [Attribution 4.0 International (CC BY 4.0)] 


\section{BACKGROUND}

An orofacial cleft comprises of cleft lip with / without cleft palate which affects children worldwide. It is found in $1-2$ per 1,000 live births and have major consequences for the affected children, their families, and the society. The birth of a child with orofacial cleft is a misery for the subject, parents and the society. Children born with this deformity definitely undergo a lot of stress especially when they start interacting with the society. Community plays a major role in the growth and the development of a child both physically and mentally. In a subject with orofacial cleft deformity this defect cannot be hidden or masked, so not only do these subjects suffer from a physical deformity but at the same time they have to face a lot of social stigma due to their appearance. Identifying all these factors and difficultiesencountered by these subjects in their day to day lives justify the design for this study.

The cell genomes contain precise instructions that can have an impact on craniofacial development. The cells are reactive to environmental signals. The extent to which the genetic and environmental factors are influenced on the cells isnot known. Since these two factors are present and interact it is difficult to rule out the exact role of each other. ${ }^{1}$ The survey of the etiopathogenesis of orofacial cleft would enable the family planning couples to be cautious and aware so that a child with orofacial congenital deformity can be prevented.

Birth defects can be defined as structural or functional abnormalities, including metabolic disorders, which are present from birth. The term congenital disorder is considered to have the same meaning and two terms are used interchangeably. ${ }^{2}$ Orofacial cleft (OFC) defects are birth defects. The diagnosis of orofacial cleft before or after birth is shocking for the parents and social environment. In India, the number of infants born every year with the cleft lip and palate is 28,600, which means 78 affected infants are born every day, or 3 infants are born with orofacial clefts every hour. ${ }^{3}$ The anatomical path that leads to the development of congenital orofacial cleft is very vital. The development of face revolves around the stomatodaeum and is contributed by five processes- the frontonasal process, a pair of maxillary process and a pair of mandibular arches. ${ }^{4}$ When the head fold forms, a prominent bulge appears on the ventral aspect of the embryo which is formed by the developing brain and the pericardium. Stomatodaeum separates the two bulges. The buccopharyngeal membrane is formed at the base of the stomatodaeum and separates it from the foregut. The fore brain is covered by the mesoderm and projects downward by overlappingthe upper portion of the stomatodaeum. The pharyngeal arches are developed within the ventral and the lateral walls in most cranial segments of the foregutand are in close association with the stomatodaeum.

These structures that lie around the stomatodaeum are responsible for the formation of the face - the frontonasal process and the fore most pharyngeal arch of each side. Mandibular arch contributes to form the lateral wall of the stomatodaeum. The dorsal end forms into a bud which in turn develops into the maxillary process. It further extends cranial to the chief part of the arch ventromedially and develops into the mandibular process. Localized thickenings are developed on either side of the ectoderm which is present over the frontonasal process. These are later known as nasal placodes.
The formation of placodes is induced by the underlying forebrain. The placodes then descend towards the under surface forming thenasal pits. These pits are totally merged below the stomatodaeum. The borders are elevated beyond the surface and form into the medial nasal process and the lateral nasal process on the medial and lateral side respectively. The maxillary process develops medially and joins primarily with the lateral nasal process and later it joins with medial nasal process and develops into the upper lip. The lateral and medial process also merges with each other. Later, the nasal pits (external nares) lose their attachments from the stomatodaeum. Considerable growth occurs in the maxillary process. At the same time the frontonasal process becomes much narrower from side to side as a result that the two external nares come closer together.

The stomatodaeum is now surrounded by the upper lip which is derived from -

- The lateral part of the lip which is of mesodermal basis and is developed from the maxillary process. The ectoderm which is present as a covering ofthe process contributes to the overlying skin.

- The frontonasal process contributes to the formation of the lip with the mesodermal basis i.e. philtrum. The ectoderm of the maxillary process grows beyond the mesoderm and joins in the midline with the maxillary process on the other side. Finally, the innervation of the skin of the upper lip is from the maxillary nerves.

- The muscles of the face (including those of the lips) are derived from the mesoderm of the second branchial arch and are therefore supplied by the facial nerve. ${ }^{5}$

From each of the maxillary process, a plate like shelf grows medially which are later known as palatal process.

The two palatal processes and the primary palate from the frontonasal process are the components from which the palate develops.

Formation of the definitive palate is by the fusion of the following -

1. Each palatal process and the posterior edge of the primary palate.

2. The two palatal processes in the midline. Fusion of the two palatal processes occur anteriorly and proceeds backward.

3. The medial border of the palatal process and the lower border of the nasal septum. This fusion divides the two nasal cavities from each other and also from the mouth.

At a later stage the mesoderm in the palate undergoes intramembranous ossification to form the hard palate. However, ossification does not extend into themost posterior portion which remains as the soft palate. The part of the palate derived from the frontonasal process forms the pre maxilla which carries the incisor teeth.

The upper lip of the hare normally has a cleft. Hence the term harelip is used for defects of the lips.

- Defects in the upper lip are formed by the failure of fusion of one or both maxillary processes with the medial nasal process. These defects may be unilateral or bilateral and also may vary in degree.

- $\quad$ Midline defects in the upper lip are formed by defective development of the lower most part of the frontonasal process.

- Defect in the midline of the lower lip is also formed by the improper fusion of the two mandibular processes. These 
defects extend into the jaw.

Defective fusion of varied components of the palate gives rise to clefts in the palate. Since, upper lip and palate are formed by the fusion of the maxillary process with the frontonasal process, clefts of the palate that extend to the anterior end are associated with cleft lip. Clefts within the palate may create an anomalous communication between nose and the mouth. These defects may be unilateral or bilateral.

The primary palate is formed by the fusion of two median nasal processes and the frontonasal process. The secondary palate is formed by the fusion of the two palatal processes which are the outgrowths of the maxillary processes.

Historically the first evidence of orofacial cleft in the literature was focussed mainly around the religion, superstition and charlatanism. The Romans and Spartans abolished the children with clefts as they were believed to be sources of evil spirits. It was also believed that Greeks ignored the existence of these defects. ${ }^{5}$ In the past, orofacial cleft was considered as a sign of horror. During the ancient period, many congenital deformities, including orofacial clefts were thought to be due to existence of evil spirits within the affected children. ${ }^{6}$

Infants with deformities of the face were considered unfit and these infants were abolished from the clans and were left alone in the desert to die. This kind of practice is still prevailing even today among the African clans. In Sparta, these ill-fated new-borns were believed to be deserted whereas in Rome, they were deliberately left to drown in the river or sometimes they were even thrown off from higher altitude. Plato, a wellknown philosopher opposed this practice and explained it in one of his dialogues in the Republic, saying that it was a method ofeliminating the evil spells and conserving the purity of the race. George Dorrance had documented the presence of cleft palate within the skull of a mummy, which makes it clear that Egyptians were aware of this deformity. During the Mediterranean civilization, children with these clefts were believed to have supernatural powers. ${ }^{7}$

According to Keating, deformities like harelip were believed to be formed due to the gazing of a pregnant woman at a person, who was having the same kind of defect. ${ }^{8}$ The scarce availability of very few records of orofacial cleft deformity from the early period may be due to their customary or religious practices and even if the child survived the earlier weeks the chances of thriving were poor. The developmental genesis of all individuals is at puberty which is a vital process. It varies among individuals. In females it occurs between ages of 10 and 14 years and males between ages of 12 and 16 years. During puberty the series of hormonal changes result in physical development of sexually mature adults. The main organ system involved in puberty is the reproductive system. The changes the individual undergoes during puberty allow the reproductive system to become fully functional. By the end of puberty, both males and females are fertile and are able to reproduce. The endocrine system is the other major role player in puberty. The hypothalamus, pituitary gland, adrenal glands, ovaries, and testes all produce hormones involved in the changes of puberty. The hormones produced affect multiple systems within the body. ${ }^{9}$

The age range of $35-45$ years is often considered as beginning of advanced paternal age. Men above 45 years' experience decreased fertility. Infants born to fathers with advanced paternal age had a higher risk of premature birth, low birth weight, low Apgar scores, higher incidence of newborn seizures and birth defects such as cleft palate and congenital heart disease. This can be attributed to a decline in testosterone as a consequence of ageing, sperm degradation and poorer semen quality. The damaged DNA gets incorporated into the cells of the offspring. These hereditary mutations contribute to the association of paternal age with disorders in the off springs like autism. Studies have shown that the risk of autism begins to increase when the paternal age is 30 , plateaus after 40 and then increases again at 50.10

This study intended to explore the association between paternal age and occurrence of orofacial clefts.

\section{METHODS}

The present study is a case control study. Ethical approval was obtained from Institutional Ethics Committee. Informed consent was obtained from all study participants. The study duration was from 2009 to 2019 . After sample size estimation, parents of 1000 orofacial cleft cases and 250 healthy controls who belonged to South India were included in the study. The subjects were individuals who visited for their review following treatment of the orofacial clefts. Control group consisted of healthy subjects without orofacial cleft or any congenital disorder who visited the above-mentioned institution for other ailments. A questionnaire was distributed to the study participants which was translated in local languages to collect details on paternal age at the time of conception.

\section{Statistical Analysis}

Statistical analysis was performed using SPSS version 23. Chi square test was used to find the association of paternal age with occurrence of orofacial clefts. $p<0.05$ was considered statistically significant.

\section{RESULTS}

\begin{tabular}{|c|c|c|c|c|}
\hline \multirow{2}{*}{\multicolumn{2}{|c|}{ Mother's Age }} & \multicolumn{2}{|c|}{ Group } & \multirow{3}{*}{$\begin{array}{c}\text { Total } \\
53\end{array}$} \\
\hline & & Cases & Control & \\
\hline \multirow{2}{*}{$<19$} & Frequency & 47 & 6 & \\
\hline & $\%$ & $4.7 \%$ & $2.4 \%$ & $4.2 \%$ \\
\hline \multirow{2}{*}{$20-24$} & & 264 & 76 & 340 \\
\hline & Frequency & $26.4 \%$ & $30.4 \%$ & $27.2 \%$ \\
\hline \multirow{2}{*}{$25-29$} & $\%$ & 475 & 107 & 582 \\
\hline & & $47.5 \%$ & $42.8 \%$ & $46.6 \%$ \\
\hline \multirow{2}{*}{$30-34$} & Frequency & 181 & 49 & 230 \\
\hline & $\%$ & $18.1 \%$ & $19.6 \%$ & $18.4 \%$ \\
\hline \multirow{2}{*}{$35-39$} & Frequency & 33 & 12 & 45 \\
\hline & $\%$ & $3.3 \%$ & $4.8 \%$ & $3.6 \%$ \\
\hline \multirow{2}{*}{ Total } & Frequency & 1000 & 250 & 1250 \\
\hline & $\%$ & $100.0 \%$ & $100.0 \%$ & $100.0 \%$ \\
\hline \multicolumn{5}{|c|}{$\begin{array}{l}\text { Table 1. Distribution of Subjects Based on } \\
\text { Mother's Age at the Time of Their Birth }\end{array}$} \\
\hline iare $=$ & $\mathrm{P}=0.191 \mathrm{~ns}$ & & & \\
\hline
\end{tabular}

Among the 1000 cases, 291 had cleft lips, 531 had cleft lip and palate and 178 had cleft palate. Among the cases, $46.4 \%$ fathers belonged to 30 - 34 years of age group and $25 \%$ belonged to 25 - 29 years of age group. In the control group, 38 $\%$ belonged to 30 - 34 years of age group and $24.8 \%$ belonged to 25 - 29 years of age group. The association between father's 
age and occurrence of orofacial cleft was statistically significant.

The mean paternal age of cases was 32.33 for cleft lip, 32.04 for cleft lip and palate and cleft palate 32.22. There was a statistical significance with respect to father's age.

\begin{tabular}{|c|c|c|c|c|}
\hline \multirow{2}{*}{\multicolumn{2}{|c|}{ Father's Age }} & \multicolumn{2}{|c|}{ Group } & \multirow{3}{*}{$\begin{array}{c}\text { Total } \\
29\end{array}$} \\
\hline & & Study & Control & \\
\hline \multirow{2}{*}{$20-24$} & Frequency & 21 & 8 & \\
\hline & $\%$ & $2.1 \%$ & $3.2 \%$ & $2.3 \%$ \\
\hline \multirow{2}{*}{$25-29$} & Frequency & 250 & 62 & 312 \\
\hline & $\%$ & $25.0 \%$ & $24.8 \%$ & $25.0 \%$ \\
\hline \multirow{2}{*}{$30-34$} & Frequency & 464 & 95 & 559 \\
\hline & $\%$ & $46.4 \%$ & $38.0 \%$ & $44.7 \%$ \\
\hline \multirow{2}{*}{$35-39$} & Frequency & 206 & 56 & 262 \\
\hline & $\%$ & $20.6 \%$ & $22.4 \%$ & $21.0 \%$ \\
\hline \multirow{2}{*}{$40-44$} & Frequency & 53 & 26 & 79 \\
\hline & $\%$ & $5.3 \%$ & $10.4 \%$ & $6.3 \%$ \\
\hline \multirow{2}{*}{$>45$} & Frequency & 6 & 3 & 9 \\
\hline & $\%$ & $0.6 \%$ & $1.2 \%$ & $0.7 \%$ \\
\hline \multirow{2}{*}{ Total } & Frequency & 1000 & 250 & 1250 \\
\hline & $\%$ & $100.0 \%$ & $100.0 \%$ & $100.0 \%$ \\
\hline \multicolumn{5}{|c|}{$\begin{array}{l}\text { Table 2. Distribution of Subjects Based on } \\
\text { Father's Age at the Time of Their Birth. }\end{array}$} \\
\hline$-\mathrm{squ}$ & $742 \mathrm{P}=0.01$ & & & \\
\hline
\end{tabular}

\section{DISCUSSION}

The marriageable age for women at 20 - 25 years and men at 30 - 35 years is the usual trend carried out in Indian Population. The mean age at effective marriage for females stood at 21.2 years in 2011 and among the major states, the highest mean age at effective marriage was 22.6 years for Kerala and the lowest was 20.3 years for West Bengal.11 Moreover, $95 \%$ of women were married by the age of 25 years, whereas the same percentage of men were married by age of 32.12

According to Golalipour MJ et al. ${ }^{13}$ Jagomagi et al..$^{14}$ and Fathololumi et al. ${ }^{15}$ as well as a study by Abramowic et al.16 reported that there was no association between the type of cleft and maternal age. Vallino - Napoli et al. ${ }^{17}$ Bille and colleagues. ${ }^{18}$ reported that the incidence of cleft lip and / or palate probably increases with maternal age.

Materna - Kiryluk A et al. ${ }^{19}$ found a positive association between advanced paternal age and hypospadias, cleft palate, and cleft lip (with or without cleft palate). The reason could be genetic changes in sperm associated with advanced paternal age which could lead to an increased risk for birth defects in offspring. Bille et al. ${ }^{17}$ found that both advanced maternal age and paternal age were associated with cleft lip with or without cleft palate. Advanced paternal age but not maternal age increased the risk of cleft palate only.

In our study, among the cases orofacial cleft was more prevalent in the age group of 25 - 29 years followed by 20 - 24 years, $30-34$ years, less than 19 years, 35 - 39 years, of mother's age (Fig. 1). Not much of significant difference was noted in control group. In accordance to our study, Gilmore et al. ${ }^{20}$ found maternal age 20 - 24 years produced 34 percent of all cleft children. De Roo et al. ${ }^{21}$ was the first to report a greater relative risk for isolated CL $\pm \mathrm{CP}$ among the 608 infants of mothers $<20$ years compared to older mothers. According to our results, the association of orofacial cleft and father's age was significant. The occurrence of orofacial clefts was highest for father's age range of 30 - 34 years followed by 25 - 29 years, $35-39$ years, $40-44$ years, $20-24$ years and $>45$ years (Fig 2 ) and a similar distribution was noted in control group. The results of the study conducted by Menegotto et al. ${ }^{22}$ revealed that mothers average age was 25.3 and fathers was 29 years. Their study correlates that maternal or paternal age has no effect on cleft series and our study correlates with their finding. In the study by González et al. ${ }^{23} 835$ cleft subjects had mean age of paternal age as 29.5 and maternal age as 27 years.

The results of this study statistically suggested that 46.4 percent of the paternal study group was in $30-34$ years of age group which suggested that higher age group was at risk. Both study and control groups were matched with respect to age to eliminate the effect of age as a confounding factor. In the study group it was found that significant association was present between paternal age and occurrence of cleft.

The inference of this result is that $<30$ is the ideal age for bearing a healthy child. Studies revealed that both younger and older age group are more vulnerable to non- syndromic orofacial clefts. In our study fathers age had an association with the birth of an orofacial cleft. The only explanation is genetic changes in the germ line due to sperm DNA denaturation during the developmental stages of foetus. Genetic changes in sperm can be associated with advanced paternal age. In younger age groups sperm changes can occur due to active lifestyle pattern.

\section{CONCLUSIONS}

Father's age had significant association with the birth of an orofacial cleft. Older fathers may contribute to the risk of orofacial cleft deformities to the unborn children. The earlier paternal age may be ideal for giving birth to a child without orofacial cleft. Men who delay fatherhood should consult their doctor and consider banking sperm before the age of $35 .{ }^{10}$ This fact may be of use to sex counsellors who counsel the parents about implications of late pregnancies. It may also be utilized by government agencies to encourage married couples to plan their offspring's early thereby reducing the risk of giving birth to a child with orofacial cleft deformities.

Data sharing statement provided by the authors is available with the full text of this article at jemds.com.

Financial or other competing interests: None.

Disclosure forms provided by the authors are available with the full text of this article at jemds.com.

\section{REFERENCES}

[1] Poswillo D. The aetiology and pathogenesis of craniofacial deformity. Development 1988;103(Suppl):207-12.

[2] World Health Organisation. Management of birth defects and haemoglobin disorders: report of a joint WHO-March of dimes meeting. Geneva, Switzerland: WHO 2006.

[3] Mossey P, Little J. Addressing the challenges of cleft lip and palate research in India. Indian J Plast Surg 2009;42(Suppl):9-18.

[4] Datta AK. The alimentary system Essentials of human embryology. $4^{\text {th }}$ edn. Current Books International Publishers 2013: p. 129.

[5] Bhattacharya S, Khanna V, Kohli R. Cleftlip: the historical perspective. Indian J Plast Surg 2009;42(Suppl):S4-8.

[6] Converse JM, Hogan VM, McCarthy JG. Cleft lip and palate. 
In: Converse JM, ed. Reconstructive Plastic Surgery. $2^{\text {nd }}$ edn. Philadelphia: Saunders 1977: p. 1930.

[7] Oritz-Monasterio F, Serrano RA. Cultural aspects of cleft lip and palate treatment. In: Grabb WC, Rosenstein W, Bzoch KR, eds. Cleft Lip and Palate. Boston: Little Brown 1971.

[8] Keating JM. Cyclopaedia of the diseases of the children. Philadelphia: Lippincott 1889.

[9] Breehl L, Caban O. Physiology, puberty. Treasure Island (FL): StatPearls Publishing 2018.

[10] https://www.sciencedaily.com/releases/2019/05/1901 3081409.htm

[11] Women and Men in India. 15th Issue. New Delhi: Central Statistics Office 2013.

[12] De Desai S. Gender scripts and age at marriage in India. Demography 2010;47(3):667-87.

[13] Golalipour MJ, Kaviany N, Qorbani M, et al. Maternal risk factors for oral clefts: a case-control study. Iran J Otorhinolaryngol 2012;24(69):187-92.

[14] Jagomagi T, Soots M, Saag M. Epidemiologic factors causing cleft lip and palate and their regularities of occurrence in Estonia. Stomatologija 2010;12(4):105-8.

[15] Fathololumi MR, Fattahi BA, Nuhi S, et al. Prevalence of cleft palate and cleft lip among 20000 Iranian neonates. Pejouhandeh 2007;12(1):31-4.

[16] Abramowicz S, Cooper ME, Bardi K, et al. Demographic and prenatal factors of patients with cleft lip and cleft palate: a pilot study. J Am Dent Assoc 2003;134(10):13716.

[17] Vallino-Napoli LD, Riley MM, Halliday J. An epidemiologic study of isolated cleft lip, palate, or both in Victoria, Australia from 1983 to 2000. CleftPalate Craniofac J 2004;41(2):185-94.

[18] Bille C, Skytthe A, Vach W, et al. Parent's age and the risk of oral clefts. Epidemiology 2005;16(3):311-6.

[19] Materna-Kiryluk A, Wisniewska K, Badura-Stronka M, et al. Parental age as a risk factor for isolated congenital malformations in a polish population. Paediatr Perinat Epidemiol 2009;23(1):29-40.

[20] Gilmore SI, Hofman SM. Clefts in winsconsin: incidence and related factors. Cleft Palate J 1966;3:186-99.

[21] DeRoo LA, Gaudino JA, Edmonds LD. Orofacial cleft malformations: associations with maternal and infant characteristics in Washington State. Birth Defects Res A Clin Mol Teratol 2003;67(9):637-42.

[22] Menegotto BG, Salzano FM. Epidemiology of oral clefts in a large South American sample. Cleft Palate Craniofac J 1991;28(4):373-7.

[23] González BS, López ML, Rico MA, et al. Oral clefts: a retrospective study of prevalence and predisposal factors in the State of Mexico. J Oral Sci 2008;50(2):123-9. 